\title{
COMBINING METHODOLOGICAL TOOLS FOR THE OPTIMUM 3D MODELLING OF NTUA CAMPUS
}

\author{
I. Pispidikis, E. Tsiliakou, D. Kitsakis, K. Athanasiou, E. Kalogianni, T. Labropoulos, E. Dimopoulou* \\ School of Rural and Surveying Engineering, National Technical University of Athens, 9 Iroon Polytechneiou str, 15780 Zografou, \\ Greece (pispidikisj@yahoo.gr; eva.tsiliakos@gmail.com; dimskit@yahoo.gr; catherineathanasiou@gmail.com; \\ efkaloyan@gmail.com tassos.labropoulos@,gmail.com; efi@survey.ntua.gr)
}

Commission VI, WG VI/4

KEY WORDS: 3D modelling, interoperability, 3D Campus, CityGML, BIM, Web Services

\begin{abstract}
:
Rapid urbanisation relates to increased space requirements above and below ground and the development of complex structures. This profound need attracted increasing interest for the collection, modelling, management, visualisation and dissemination of 3D objects through various application fields, such as: 3D Cadastre, 3D City Modelling and Building Information Modelling. Contemporary advances in GIS technology, Geo-Web services and computer graphics facilitate the development of such models accompanied by semantic, geometrical and topological information, while the use of international standards enables the communication and interoperability between the systems. The aim of this paper is to combine state-of-the art methodologies and technologies for the development of semantically enriched 3D models for the Campus of the National Technical University of Athens in Greece. The result is a web-based 3D Campus map that integrates these models as Web Services, providing access to management and navigation for the campus area and can also be used for maintenance purposes from the various NTUA Departments. To this end, the database schema has been designed compatible with CityGML, while attention was given to interoperability issues that arise from differently derived 3D models which had to be stored and visualised while retaining their characteristics.
\end{abstract}

\section{INTRODUCTION}

Recent advancements in 3D digital modelling techniques have boosted the production of 3D physical models of buildings and urban infrastructures worldwide (Becker et al. 2013).

The last two decades, 3D city modelling has gained progressively ground as a tool for various advanced applications, leading to the emergence of detailed 3D city models entailing, not only geometrical and topological, but also semantic information (Dimopoulou et al., 2014; Gózdz et al., 2014). This need was driven on the one hand by revolutionary developments in 3D modelling techniques, and by the emergence of various applications in fields related to smart city planning, simulations and decision-making on the other. Biljecki et al. (2015) present 29 use cases and more than a hundred different application domains of 3D city models, for diverse purposes. Prominent examples are indoor navigation (Lee et al., 2014), emergency response (Tashakkori et al., 2015; Chen et al., 2014), energy demand estimation (Krüger \& Kolbe, 2012) disaster management (Zlatanova \& Holweg, 2004; Kolbe et al., 2008), urban and telecommunication planning (Lamberti et al., 2011) and 3D Cadastre (Oosteroom, 2013; Góźdź et al., 2014). Additionally, Morton et al. (2012) identified over one thousand 3D City models worldwide, being used in smart cities, university campuses, commercial properties, shopping malls, airports, museums, and more.

3D city models come in many different flavours. Some of the most commonly used technologies for 3D city models are Geographic Information Systems (GIS), while for building-scale models Building Information Model (BIM) is mostly used. BIM and GIS share foundation concepts, although they refer to different spatial scales and modelling levels and thus, various data exchange standards, protocols and formats have been developed to serve the needs of each domain. Industry
Foundation Classes (IFC) is the most common open standard format for exchanging BIM models across multiple platforms, while City Geography Markup Language (CityGML) constitutes the most commonly-used data model for 3D GIS. IFC is a semantic, object-oriented data model using a hierarchical spatial structure to store building information focusing on the structural and design characteristics of the buildings.

The interrelation between different 3D city models is perplexed even more considering the wide variety of platforms available for storing, modelling and visualising them, while several problems (data loss, topological inconsistencies. etc.) may occur during the conversion from a 3D city model to another (Zlatanova et al., 2012). 3D City models are used in GIS/CAD tools, 3D web viewers and 3D game engines. The rapid development of computer graphics and the web leads to the gradual transition to $3 \mathrm{D}$ web visualisation.

Above mentioned technological advances have also led to the development of virtual 3D campus models, for educational, management and navigation purposes, serving evacuation and security purposes. A variety of such research is available in literature. Singh et al., (2014), note that many educational institutes have developed and published their own 3D campus models with ESRI CityEngine, combined with digital camera images. Kulkarni et al., (2017), combined the 2D campus maps with 3D campus model to present the campus' current status in GIS. They addressed interoperability, accuracy and efficiency in 3D modelling representations by the synergy of Google Earth, SketchUp and QGIS. Anh et al. (2017), developed a virtual campus using GIS data and 3D GIS and focus on the system's potentials for navigation and management. Maines and Tang (2015) explored virtual campus tours along with the problems of interior navigation. Rahmat et al., (2017), aimed to introduce and geolocate their campus' buildings in interactive and innovative ways, via $3 \mathrm{D}$ modelling and virtual reality technology. 
Given this background, the aim of this paper is to combine different 3D modelling methodological tools and techniques to develop a semantically enriched 3D campus model that can be used for navigation and maintenance. The study area is the campus of the National Technical University of Athens (NTUA), commissioned by the Technical Services of the University. As a result, a 3D Web campus map has been created, providing a tool to support decision-making about the asset management of the campus. The 3D NTUA Campus is a cutting-edge technological tool that improves navigation within the campus and provides access to management and navigation information, also serving security purposes.

The paper is structured as follows: first the need for 3D modelling and management is discussed referring to technologies, standards and guidelines that are currently being used in various application areas. A brief research on 3D campus developments is presented, highlighting the principal aim of this paper. Following, an overview of 3D modelling techniques is provided, in relation to existing standards, raising compatibility and integration issues with different models or modelling techniques and concludes to the most efficient combination of database schemas and Web services for the publication of $3 \mathrm{D}$ interactive scenes. The next section presents the NTUA campus project along with the applied methodology and its implementation. The last sections present the results and conclusions concerning the modelling process' performance, in terms of efficiency and precision both regarding visualisation and semantics.

\section{3D DATA MODELLING \& MANAGEMENT}

Physical reality needs to be virtually and digitally represented in 3D, enabling GIS and BIM users to be more creative by experimenting with different processes. Synergy between GIS and BIM is the key for optimum design and analysis, reducing time and cost in various applications, and certainly, providing the end users with better services and models characterised by high end quality and robustness. IFC and CityGML, as information models defining object geometries, semantics and their inter-relationships, are different to their core, as they 'are adapted to requirements of the domains they originate from' (Hijazi \& Donaubauer, 2017).

A lot of research has been carried out to minimize the GIS-BIM gap, as in the case of Isikdag and Zlatanova (2009) who attempted a two-part transformation of both the geometric and semantic datasets of their models, or like Bittner et al., (2006) and Boyes et al., (2018) who attempted a systematic mapping of conflicting semantic data structures. Such research efforts, have triggered developments including CityGML Application Domain Extension (ADE) (van Berlo and de Laat, 2011) and the intermediary Unified Building Model (El-Mekawy, Östman and Hijazi, 2012). The migration of models between IFC and CityGML is being tested both ways in terms of semantics, information loss and in a higher Level of Detail (LoD).

The interoperability of 3D city models, especially the integration of 3D GIS and BIM has been a significant research question (Kang et al., 2015; Deng et al., 2016; Jusuf et al., 2017). Since CityGML and IFC are often chosen as the most representative data schemas for GIS and BIM respectively, the research focuses on ways of exchanging information and bringing together CityGML and IFC.

\subsection{D Modelling developments}

3D modelling in Geoinformatics area refers to descriptions of real world entities and phenomena, represented by BIM and 3D GIS, being the two main pillars for the representation and the accurate modelling and simulation of $3 \mathrm{D}$ objects. These concepts interpret 3D modelling differently, since GIS focuses more on real world modelling, while BIM on the design process (Liu et al., 2017). In the last decade there have been various successful academic and industrial efforts to create a strong and robust synergy between BIM and GIS, specifically focusing on integration processes between IFC and CityGML.

Amongst numerous integration efforts, a few are mentioned, such as the ADE of CityGML used in numerous studies (Bahu and Nouvel, 2015; Deng et al., 2016), the GeoBIM extension (Van Berlo and de Laat, 2011), the unidirectional transformation from IFC to CityGML (El-Mekawy et al., 2012), the Automatic generation of IFC model from CityGML LOD3 model (Donkers, 2013), the protralaying method on CityGML (Kolbe, 2007), the Unified Building Model (UBM) (El-Mekawy et al., 2012), the City Information Modeling (CIM) (Xun et al., 2014), the Conversion of CityGML model from IFC model through geometric division (Yu and Teo, 2014), the ExtrusionBaseModel (Geiger et al., 2015), the Semantic web technology method and the BIM/GIS-based information Extract, Transform and Load (BG-ETL) architecture (Karan et al., 2015). Abovementioned paradigms are characterized by robust 'communication' amongst different $3 \mathrm{D}$ procedures, resolving interoperability issues delicately.

\subsection{Database Schemas}

3D city models can be stored in different ways, either file-based or in a database in a hierarchically, multi-scale way. Database is considered the most significant part of the architecture of a GIS system and hence, the database schema needs to be carefully designed and structured, based on the needs of each application. 3D city models structured according to CityGML standard need to be semantically stored so that the corresponding model can be easily generated. It should be noted that although CityGML is considered an optimal standard for presenting 3D city models, international research shows that the visualisation of the latter is quite difficult to be successfully implemented (Pispidikis et al., 2016; Chaturvedi et al., 2015; Prandi et al., 2015; Prandi et al., 2013). Consequently, the implementation of a semantic spatial database is considered vital. The 3D City Database (3DCityDB) is the most suitable schema according to the CityGML standard and additionally supports the commercial SRDBMS Oracle and the Open Source RDBMS PostgreSQL (Kolbe et al., 2015). On the other hand, the commercial solution of the semantically enriched database schema is the 3D City Information Model (3DCIM) (Padsala et al., 2015), developed by ESRI, aiming to provide compact and yet simple in structure, information models. Additionally, the 3DCIM and the CityGML are considered complementary and hence, several tools were developed so to achieve interoperability of these models (Reitz et al., 2015). As a result, both 3DCIM and 3DCityDB schemas can be implemented regarding the semantic storage of $3 \mathrm{D}$ city models.

\subsection{Web Services (3D OGC Web Services, ArcGIS Server Rest Services, 3D WebGIS, etc.)}

Web Services represent significant progress in distributed GIS. Before Web Services technology was available, interoperability was mostly accomplished at the data formatting level (Fu \& Sun, 2010). With the emergence of Web Service, data and functions can be exposed as Web Services and linked on demand to build solution. This capability led OGC (Open Geospatial Consortium) to develop several geospatial Web Services. The most significant geospatial Web Services are the Web Map Service (WMS), Web Feature Service (WFS), Web Coverage Service (WCS) and Catalogue Service for the Web (CSW). Furthermore, the available 3D portrayal services are the Web 3D Service (W3DS) 
(Schilling \& Kolbe, 2010) and Web View Service (WVS) (Benjarmin, 2010). It should be noted that except of the aforementioned OGC standards, a new portrayal scene service was developed by ESRI, which allows users to share content via web scenes using ArcGIS. Specifically, a scene service is a new type of ArcGIS server web service originating from a 3D scene in ArcGIS pro.

\section{MATERIALS AND METHODS}

NTUA campus is a complex collection of features (buildings, other infrastructure facilities, parking lots, squares, bus stops, trees and vegetation, etc.), networks (roads, bicycle paths and sidewalks) and surfaces that cover around $30.000 \mathrm{~m} 2$ of infrastructure, surrounded by a natural environment of 100 hectares. The campus area is used by more than 25.000 students and staff members. Within this context, it was crucial to create an integrated 3D modelling approach, following several methodological steps and properly combining available technologies.

Methodological steps are schematically presented in Figure 1 and described at the following sub-sections.

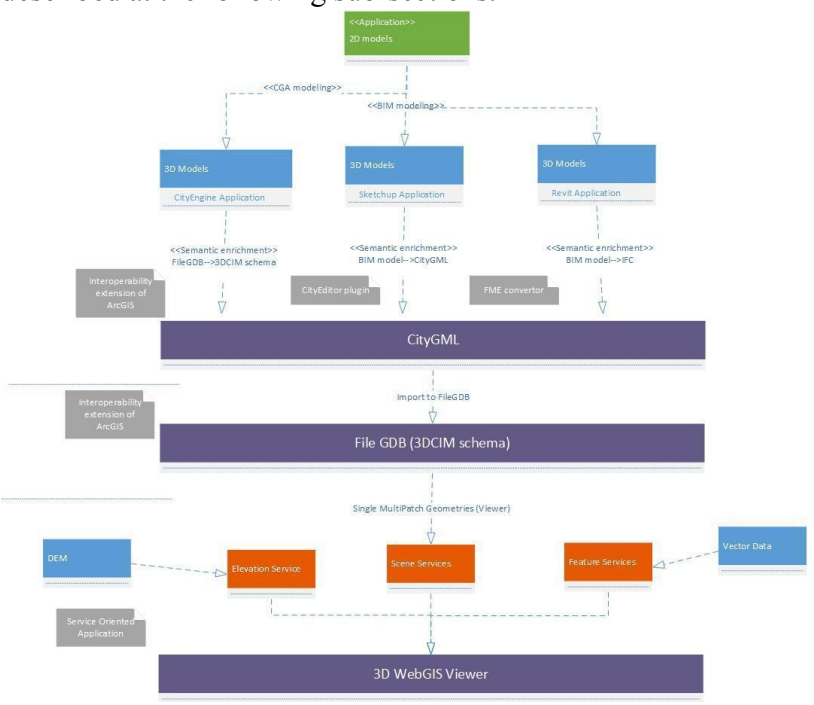

Figure 1. Methodological steps

\subsection{Data collection}

The first step was to collect all available data (both in digital raster and vector- and analogue format), to manipulate them accordingly (scanning, georeferencing, etc.) and quality check them in terms of completeness and coherence. Information about the data (that can be used as metadata) was organised for a clear overview of the availability, complexity and lack of important data that needed to be retrieved by other sources.

The Department of Technical Services of the NTUA provided data of multiple formats which needed to be processed separately. In particular, data was provided regarding:

- Buildings:

- Façades,

$\square$ Floor plans,

$\square$ Sections.

- Infrastructure networks,

- Base maps:

$\square$ Aerial Images of the wider NTUA area,

$\square$ Orthophotos,
Digital Terrain Model (DTM) \& Digital Surface Model (DSM),

$\square$ Topographic and Survey Diagrams.

Additionally, approximately 5.000 photos of buildings' façades were captured to be used for 3D models' texturing.

\subsection{Data Modelling and Storage}

Data for buildings and the related facilities was organised according to each School and/or Department they belong to and the modelling part was accordingly organised.

To achieve a semantically enriched result the data was stored at the 3DCIM, which complements and provides seamless exchange with CityGML file schema. For buildings' modelling, three different approaches were combined, using the following software (as illustrated in Figure 1):

- ESRI CityEngine,

- Trimble SketchUp Pro,

- Autodesk Revit.

Layouts, sections and floor plans were used in order to derive the footprint, shape and dimensions of the buildings and the building parts. In Figure 2 a typical façade in 2D is illustrated together with the corresponding 3D façade, modelled in ESRI CityEngine.
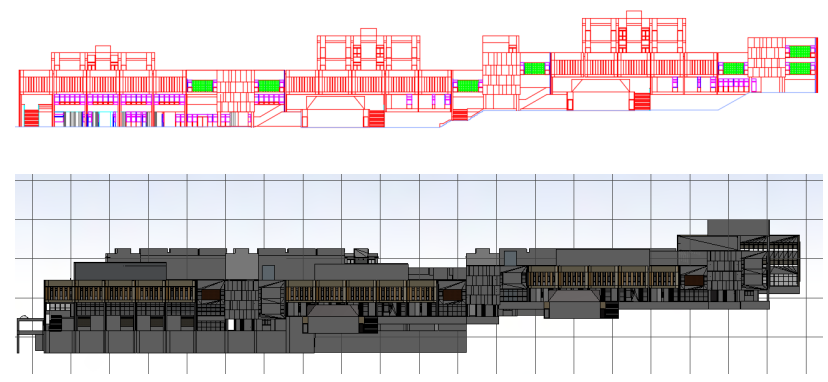

Figure 2. 2D and 3D building façades

Depending on the available data and sources, above mentioned techniques were explored and combined to generate semantically enriched 3D models.

ESRI CityEngine combines procedural modelling methods with CGA shape and split grammars (splitting a 3D object into its components: faces, edges or vertices) to generate $3 \mathrm{D}$ content, that can be semantically enriched, by applying specialised methodology. By using ESRI CityEngine, the advantage of modelling repetitive patterns was exploited. However, developing CGA rules for complex multi-storey buildings demands advanced programming skills, thus results to a time and cost demanding process. In this context, aiming at the minimisation of 3D model development time through coding, a web CGA generator tool has been developed.

The Web CGA Generator tool (Figure 3) is developed in order to minimise coding process of the CGA shape grammars regarding 3D modelling of buildings in LoD2 and LoD3. Specifically, the tool generates the desired CGA rule through a descriptive procedure. The users register the architectural data into this tool (by defining the distance both between different floors and between consecutive building elements on each floor façade) and thereafter the corresponding rule is automatically generated. The limitation of this tool is that it can successfully be used only in buildings with relatively simple architecture (four façades, flat roof, etc.). Therefore, direct development of CGA rules by the user is necessary to model complex architectural structures, e.g. buildings with complex roofs or protruding building parts. 

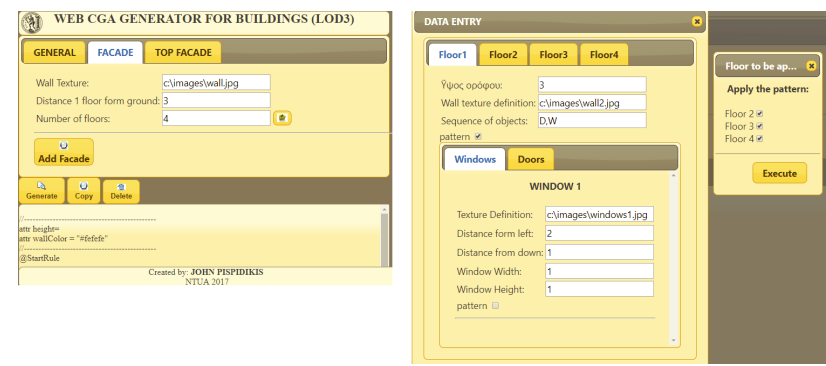

Figure 3. Web CGA Generator tool

A few issues can also be pointed out, regarding modelling with ESRI CityEngine or Trimble Sketchup. While ESRI CityEngine offers an environment of fast and large-scale modelling, in cases of complex structures, the modelling process can be overly complex, not efficient and eventually time consuming. For example, it is it is easier to use 3D obj models from the Trimble SketchUp warehouse rather than generating procedurally elements such as stairs, balconies etc.

It may be concluded that modelling with Trimble Sketchup is straightforward, it has an easy to use interface, and the connection to 3D Warehouse offers a variety of ready to use 3D models. On the other hand, textured Trimble Sketchup models (which give a more realistic visual effect than simple colours) are characterised by data loss when migrating to different software.

Developed models were then semantically enriched, to be represented in LoD1, LoD2 and LoD3 of CityGML standard and then, imported to a file Geodatabase, based on the 3DCIM schema. It should be noted that the 3DCIM schema is compatible with the File Geodatabase of ArcGIS. Consequently, the produced building models can easily be published as ArcGIS scene services. Simultaneously, by storing these data in compliance with 3DCIM schema, the automate generation of the respective CityGML is achieved by utilizing the data interoperability extension of ArcGIS (Figures 4 and 5).
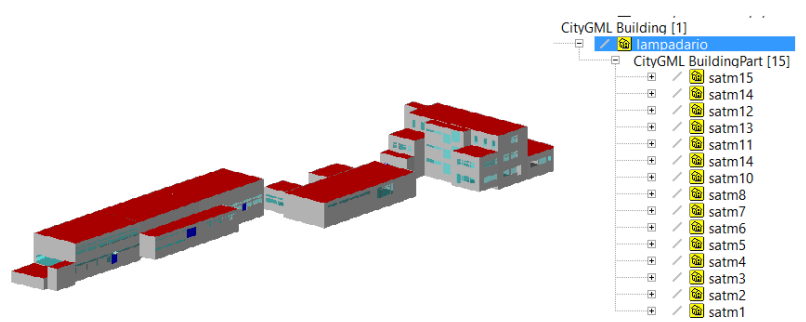

Figure 4. LoD3 building of NTUA campus
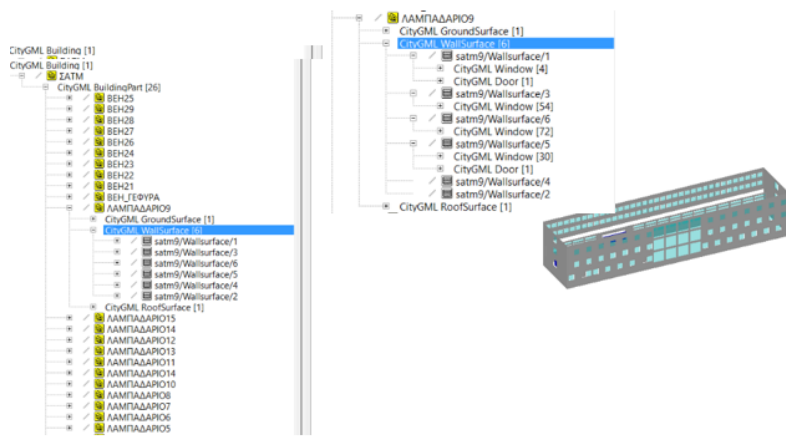

Figure 5. LoD3 building of NTUA campus with detailed semantics

\subsection{Data visualisation and dissemination}

Next, web services were published via ArcGIS online, representing the following features:

- basemaps (Map service),

- $\quad$ public transport stops (Feature service),

- trees and vegetation (Feature service),

- buildings (scene service) and

- DEM (elevation service).

The terrain, where the NTUA Campus is situated, is characterised by rather intense relief. Therefore, buildings and other structures extend on different height or depth levels (Figure 6). In order to present subterranean buildings and structures, a separate elevation service was created, adjusting DEM so that above mentioned objects are as well visible in the web-GIS viewer. The original DEM was converted to a transparent polygon and was used in combination with the custom elevation service. Additionally, the public transport stops were connected with the Athens Urban Transport Organisation telematic application and therefore, real-time information on the bus arrivals is available. Finally, all published web services were integrated into the webGIS viewer campus interface, using Web AppBuilder for ArcGIS.

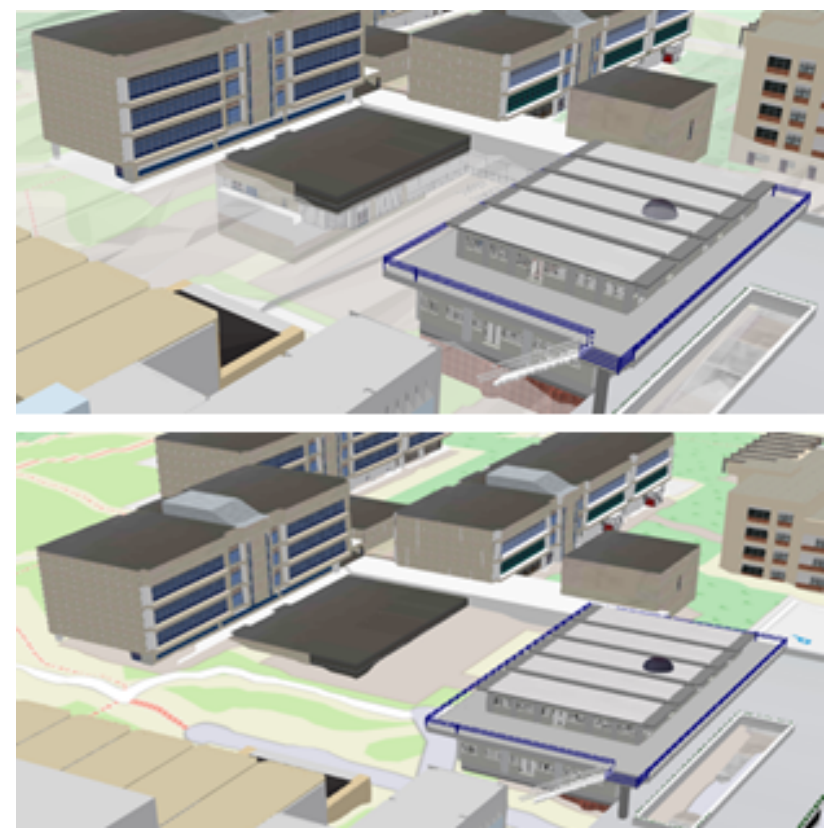

Figure 6. Visualisation of underground structures using the elevation service (top). Without the use of the elevation service underground facilities are not visible (bottom).

\section{RESULTS}

Implementation of the above-mentioned methodology, resulted in the development of an interactive 3D WebGIS viewer of the NTUA Campus (Figure 7). Users are able to navigate within NTUA facilities, trace locations of interest and move to and from the campus using public transport. City furniture such as lamps, bus stops and campus entrances is also included to the developed model (Figures 8 and 9). A variety of basemaps (OpenStreetMaps, Google Imagery and other ArcGIS Online basemaps) are available to fit as background to different users' needs. 


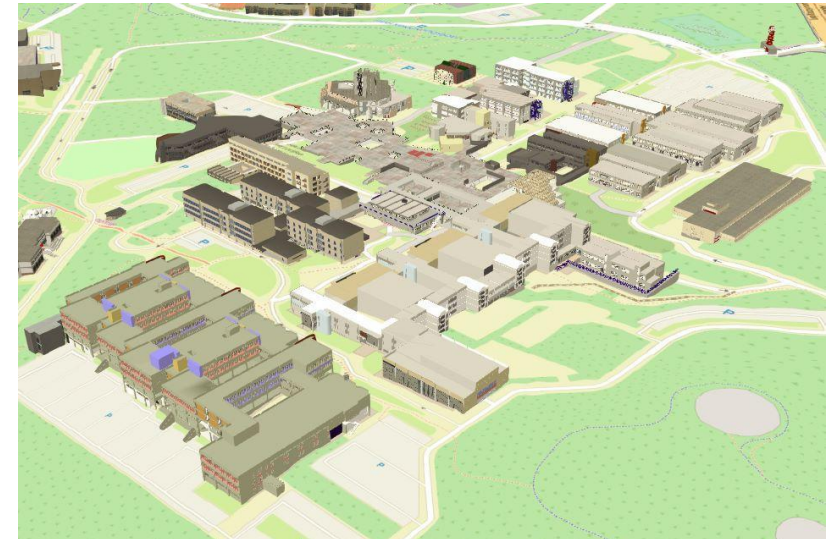

Figure 7. 3D NTUA Campus overview

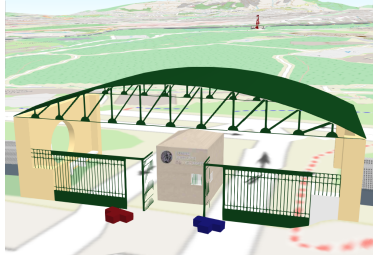

Figure 8. 3D models one of the main campus entrances modelled in Trimble SketchUp

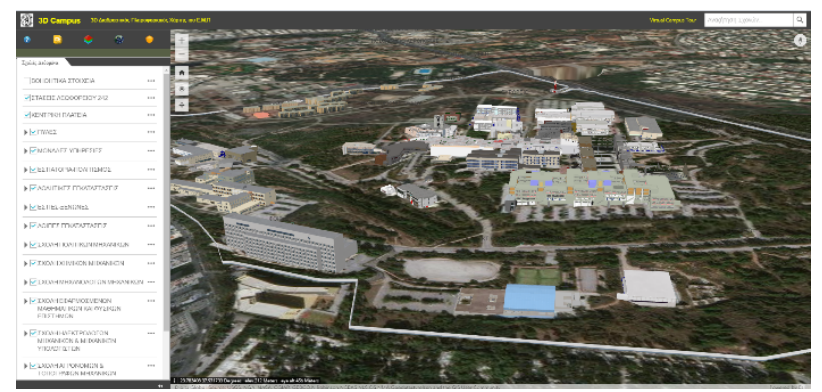

Figure 10: Interactive 3D WebGIS viewer of NTUA

Apart from navigation and comprehensive presentation capabilities, semantic enrichment of the 3D buildings' models also allows for the efficient management of the campus premises, including building and infrastructure maintenance. 3D campus model is structured in a way that it can be further extended and also used for other purposes, such as energy consumption and routing, as well as for security purposes.

\section{DISCUSSION AND CONCLUSIONS}

Exploring and combining the different tools for the creation of the 3D WebGIS NTUA Campus viewer, as presented in Section 3 , raised several challenges towards interoperability between the different components and efficiency of the developed 3D WebGIS viewer for the NTUA Campus.

With regards to the modelling process, the different modelling approaches (procedural and BIM-based modelling), dictate the issues that were to be addressed. Thus, in this Section, the difficulties and challenges faced in those approaches are briefly discussed.

\subsection{Procedural modelling with ESRI CityEngine}

The use of CGA grammar proved very efficient for 3D building modelling, especially regarding buildings with identical or similar architectural patterns (e.g. same number of windows at the same position in each façade), as a CGA rule can be multiply used or configured to generate different buildings or building parts. In the examined case study, a significant number of buildings and building parts shared similar architectural patterns, although of different dimensions. Configuration of the same CGA rule to adjust to the dimensions of each building, significantly reduced modelling procedure of such buildings. Additionally, 3D models can be easily textured without any further photogrammetric editing.

On the other hand, CGA grammar cannot address efficiently the modelling of more detailed buildings with complex architectural characteristics, or buildings with different footprints per floor. Such issues were addressed within this research through the separation of such buildings on different building parts, creating less complex geometries that can be modelled easier and faster. However, this solution may introduce redundancies to a building that is composed of separate building parts, such as double wall surfaces where neighbouring building parts touch each other. Complex architectural characteristics that could not be directly modelled through CGA grammar, such as ornaments or curves, were imported as individual 3D objects (in Collada or obj formats) and were georeferenced, scaled and textured to adjust to the building on which they pertain. This brings up issues of compatibility between the imported objects' model and the building model as derived from implementing its corresponding CGA rule. Furthermore, this approach requires the use of other 3D modelling techniques, such as Image Based Modelling or laser scanning, which increases processing time and cost. Within this field, exploitation of BIM tools provided significant contribution, especially regarding modelling of elements such as stairs, ramps or balconies. Modelling such elements using CGA grammars constitutes a very laborious task, of average visualisation results.

\subsection{BIM modelling with Trimble SketchUp}

In order to create the final 3D campus model, individual models designed in Trimble SketchUp Pro were imported to ESRI CityEngine software in Obj file format and then imported to the File Geodatabase. This procedure involves several drawbacks. To name a few: export of extensive (in terms of size and number of buildings parts/façades) models in many cases resulted in the loss of data, especially in case of material texturing. In order to resolve this issue, different export combinations were tested to achieve minimum data loss. Additionally, a number of materials was not transferred from one system to the other, while other materials were assigned different textures after the data transfer. Use of colours instead of textures (based on digital images of each structure) was implemented to cope with such issues.

Migration of Trimble SketchUp Pro models to ESRI CityEngine environment also introduces inaccuracies on model georeferencing. In some cases, adjusting export options was sufficient to resolve this problem. However, some models required to be manually relocated to their correct geolocation.

However, it should be noted that via the CityEditor plugin of Trimble Sketchup Pro, direct generation of complex CityGML models can be achieved in different LoDs. Thereafter, the generated models are automatically stored to a file Geodatabase, based on the 3DCIM schema. 


\subsection{BIM modelling using Autodesk Revit}

3D modelling process also involved modelling using Autodesk Revit software. Such models include rich semantic information regarding the building's structure and provide for high quality 3D models. Despite the benefits of Revit on development of building models, significant drawbacks emerge during conversion of Revit models to CityGML Given the significant amount of, building level information they pertain, Revit models introduce redundancies when converting to CityGML, involving data loss and inconsistencies with CityGML database schema. To address these issues, FME software was employed to assist data conversion, although the results could only suffice in case of constructions of low complexity that were modelled in low level of detail within AutoDesk Revit software.

\section{ACKNOWLEDGEMENTS}

This work is part of the Research Program «3D Visualization of the National Technical University of Athens Zografos Campus 3D Campus NTUA project», which is funded by Thomaidis Foundation. The authors would like to thank the Department of Technical Services of the National Technical University of Athens for providing the available data throughout the project process.

\section{REFERENCES}

Anh, P., Chuc, M. D., Hung, B. Q., and Thanh, N. T. N., 2017. Development of virtual campus using GIS data and 3D GIS technology: A case study for Vietnam National University, Hanoi. In: Knowledge and Systems Engineering (KSE), 2017. 9th International Conference on (pp. 281-286). IEEE.

Bahu, J. M., Nouvel, R., 2015. Development of the CityGML ADE Energy. In: Proceedings of the INSPIRE-Geospatial World Forum Conference, Lisbon, Portugal, 25-29 May 2015.

Becker, T.; Nagel, C.; Kolbe, T.H. Semantic 3D modeling of multi-utility networks in cities for analysis and 3D visualization. In Progress and New Trends in 3D Geoinformation Sciences; Springer: Berlin, Germany, 2013; pp. 41-62

Benjarmin, H., 2010. Web View Service Discussion Paper. ver 0.3.0. OpenGIS Discussion Paper. Available from: https://portal.opengeospatial.org/modules/admin/license agree ment.php?suppressHeaders $=0 \&$ access license $\mathrm{id}=3 \&$ target $=\mathrm{htt}$ p://portal.opengeospatial.org/files/?artifact id $=37257$.

Biljecki, F., Stoter, J., Ledoux, H., Zlatanova, S. and Çöltekin, A., 2015. Applications of 3D City Models: State of the Art Review. ISPRS International Journal of Geo-Information, 4(4), pp. 2842-2889.

Bittner, T., Donnelly, M. and Winter, S. 2006. Ontology and semantic interoperability. In: Largescale 3D data integration: pp.139-160.

Boyes, G., Thomson, C., \& Ellul, C. (2015). Integrating BIM and GIS: Exploring the use of IFC space objects and boundaries. Proceedings of the GISRUK.

Chatuverdi, K., Yao, Z., Kolbe, T. H., 2015. Web-based Exploration of and Interaction with Large and Deeply Structured
Semantic 3D City Models using HTML5 and WebGL. In: Wissenschaftlich-Technische Jahrestagung der DGPF und Workshop on Laser Scanning Applications, Vol. 3

Chen, L.C., Wu, C.H., Shen, T.S., and Chou, C.C., 2014. The application of geometric network models and building information models in geospatial environments for fire-fighting simulations. Computers Environment and Urban Systems, 45, pp. $1-12$.

Dimopoulou, E., Tsiliakou, E., Kosti, V., Floros, G., \& Labropoulos, T. (2014, November). Investigating integration possibilities between 3D modelling techniques. In Proceedings of the 9th 3DGeoInfo Conference (pp. 1-16).

Dimopoulou, E., Kitsakis, D., and Tsiliakou, E., 2015. Investigating correlation between legal and physical property: possibilities and constraints. In: Proc. SPIE 9535, Third International Conference on Remote Sensing and Geoinformation of the Environment (RSCy, 2015), 95350A (2015); doi: $\quad 10.1117 / 12.2192572$, https://doi.org/10.1117/12.2192572

Deng, Y., Cheng, J.C.P., Anumba, C., 2016. Mapping between BIM and 3D GIS in different level of details using schema mediation and instance comparison. Autom. Constr., 37, pp. 121.

Donkers, S., 2013. Automatic Generation of CityGML LoD3 Building Models from IFC Models. Master's Thesis, Department of GIS Technology, TU Delft, Delft, The Netherlands.

El-Mekawy, M., Östman, A., and Hijazi, I., A., 2012. Unified Building Model for 3D Urban GIS. ISPRS International Journal of Geo-Information, 1, pp. 120-145.

Fu, P., and Sun, J., 2010. Web GIS: principles and applications. USA: Esri Press.

Geiger, A., Benner, J., Haefele, K.H., 2015. Generalization of 3D IFC Buildings Models. In: 3D Geoinformation Science, Benner, J., Haefele, K.H., (Eds.), Springer International Publishing, Cham, Switzerland, 2015; pp. 19-35.

Gózdz, K., Pachelski, W., van Oosterom, P.J.M., Coors, V., 2014. The possibilities of using CityGML for 3D representation of buildings in the Cadastre. In: Proceedings of the 4th International FIG 3D Cadastre Workshop, Dubai, UAE, 9-11 November 2014, pp. 339-361.

Hijazi, I., \& Donaubauer, A. (2017). Integration of building and urban information modeling-opportunities and integration approaches. Geoinformationssysteme.

Isikdag, U. and Zlatanova, S. 2009. Towards defining a framework for automatic generation of buildings in CityGML using Building Information Models. In: 3D Geo-Information Sciences, Lecture Notes in Geoinformation and Cartography. Berlin, Heidelberg: Springer Berlin Heidelberg, pp.79-96.

Karan, E.P., Irizarry, J., Haymaker, J., 2015. BIM and GIS Integration and Interoperability Based on Semantic Web Technology. J. Comput. Civ. Eng., 30, pp. 1-11.

Kang, T.W., Hong, C.H., 2015. A study on software architecture for effective BIM/GIS-based facility management data integration. Autom. Constr., 54, pp. 25-38. 
Kolbe, T.H., 2007. CityGML-3D Geospatial and Semantic Modelling of Urban Structures. In: Proceedings of the GITA/OGC Emerging Technology Summit 4, Washington DC, 21-23 March 2007, USA.

Kolbe, T.H., Gröger, G., Plümer, L., 2008. CityGML - 3D City Models for Emergency Response. In: Zlatanova, S., Li, J. (Eds.), Geospatial information technology for emergency response. Taylor \& Francis, London, pp. 257-274.

Kolbe, T. H., Yao, Z., Nagel, C., Kunde, F., Willkom, P., Hudra, G., Muftuoglou, A., \& Herreruela, J., 2015: 3D City Database for CityGML Version 3.0.0. Institute for Geodesy and Geoinformation Science.

Krüger, A., Kolbe, T.H., 2012. Building analysis for urban energy planning using key indicators on virtual 3D city modelsThe energy atlas of Berlin. Int. Arch. Photogramm. Remote Sens. Spat. Inf. Sci. 2012, XXXIX-B2, pp. 145-150.

Kulkarni, K. R., Yatish, C. H., Kamble, K. P., Kulkarni, A. A., and Bangi, S. C., 2017. Development of 2D Map and 3D Model of GIT Campus using GIS Technology. International Journal of Engineering and Technology, 4 (6), pp. 2597-2601.

Lamberti F., Sanna A., Ramirez E., 2011. Web-based 3D visualization for intelligent street lighting. In: Proceedings of the 16th International Conference on 3D Web Technology (Web3D '11), Paris, France 2011, pp. 151-154.

Lee, J., Li, K., Zlatanova, S., Kolbe, T., Nagel, C. and Becker, T., 2014. OGC IndoorGML. Available from: http://www.opengeospatial.org/standards/indoorgml.

Liu, X., Wang, X., Wright, G., Cheng, J. C., Li, X., \& Liu, R. (2017). A State-of-the-Art Review on the Integration of Building Information Modeling (BIM) and Geographic Information System (GIS). ISPRS International Journal of Geo-Information, 6(2), 53.

Maines, C., Tang, S., 2015. An Application of Game Technology to Virtual University Campus Tour and Interior Navigation. In: Developments of E-Systems Engineering (DeSE), pp. 341-346.

Morton, P.J., Horne, M., Dalton, R.C., Thompson, E.M., 2012. Virtual city models: Avoidance of obsolescence. In Digital Physicality, In: Proceedings of the 30th eCAADe Conference, Prague, Czech Republic, September 2012.

Padsala, R., Coors, V., 2015. Conceptualizing, Managing and Developing: A Web Based 3D City Information Model for Urban Energy Demand Simulation. In: $U D M V$, pp. 37-42.

Pispidikis, I., Dimopoulou, E. 2016. Development of a 3D WebGIS system for retrieving and visualizing CityGML data based on their semantic characteristics by using free and open source technology. In: ISPRS Annals of Photogrammetry, Remote Sensing \& Spatial Information Sciences, 4(2).

Prandi, F., De Amicis, R., Piffer, S., Soave, M., Cadzow, S., Gonzalez Boix, E., and D'Hont, E., 2013. Using CityGML to deploy Smart-City services for Urban Ecosystems. In: International Archives of the Photogrammetry, Remote Sensing and Spatial Information Sciences, Volume XL-4/W1, pp. 87-92.
Prandi, F., Devigili, F., Soave, M., Di Staso, U., \& De Amicis, R., 2015. 3D web visualization of huge CityGML models. In: ISPRS-International Archives of the Photogrammetry, Remote Sensing and Spatial Information Sciences, 1, pp. 601-605.

Rahmat, R. F., Muchtar, M. A., Hizriadi, A., \& Syahputra, M. F., 2018. Virtual reality interactive media for universitas sumatera utara-a campus introduction and simulation. In: Journal of Physics, Conference Series, 978 (1), p. 012101. IOP Publishing.

Reitz, T., Schubiger-Banz, S., 2014. The Esri 3D city information model. In: IOP Conference Series: Earth and Environmental Science, 18, (1), p. 012172). IOP Publishing.

Schilling, A., Kolbe, T. H., 2010. Draft for Candidate OpenGIS Web 3D Service Interface Standard. ver. 0.4.0. OpenGIS Discussion Paper.

Singh, S. P., Jain, K., Mandla, V. R., 2014. Image based Virtual 3D Campus modeling by using CityEngine. American Journal of Engineering Science and Technology Research, 2(1), pp. 01-10.

Tashakkori, H., Rajabifard, A., Kalantari, M., 2015. A new 3D indoor/outdoor spatial model for indoor emergency response facilitation. Build. Environ., 89, pp. 170-182.

van Berlo, L., de Laat, R., 2010. Integration of BIM and GIS: The development of the CityGML GeoBIM extension. In: Proceedings of the 5th International 3D GeoInfo Conference, Berlin, Germany, November 2010.

van Oosterom, P.J.M., 2013. Research and development in 3D cadastres. Computers Environment \& Urban Systems, 40, pp. 16.

Xun, X.; Lieyun, D.; Hanbin, L.; Ling, M. From building information modeling to city information modeling.

J. Inf. Technol. Constr. 2014, 19, 292-307.

Yu, S.-C.; Teo, T.-A. The Generalization of BIM/IFC Model for Multi-Scale 3D GIS/CityGML Models. Available online: http://a-a-r-s.org/acrs/index.php/acrs/acrs-

overview/proceedings-1? view $=$

publication\&task=show\&id=1393 (accessed on 12 May 2018).

Zlatanova, S., Holweg, D., 2004. 3D Geo-information in emergency response: a framework. In: Proceedings of the Fourth International Symposium on Mobile Mapping Technology, 29-31 March, Kunming, China.

Zlatanova, S., Stoter, J., \& Isikdag, U. (2012). Standards for Exchange and Storage of 3D Information: Challenges and Opportunities for Emergency Response. In: Proceedings of the 4th International Conference on Cartography \& GIS, Albena.

Jusuf, S.K., Mousseau, B., Godfroid, G., Soh, J.H.V. 2017. Path to an Integrated Modelling between IFC and CityGML for Neighborhood Scale Modelling. Urban Sci., 1(3), 25. 